\title{
Impactos do Programa NERDS da Fronteira para a Consolidação do Uso das TICs na Educação em Ponta Porã
}

\author{
Danilo O. Fistarol ${ }^{1}$, Higor R. Coutinho ${ }^{1}$, Sávio Vínicius A. B. Cantero ${ }^{1}$, Amaury A. \\ Castro Jr${ }^{1}$. \\ ${ }^{1}$ Universidade Federal de Mato Grosso do Sul - Campus Ponta Porã (CPPP) \\ Rua Itibiré Vieira, s/n - Residencial Julia Oliveira Cardinal BR 463 - Km 4,5 \\ 79.907-414 - Ponta Porã - MS - Brasil \\ \{danilofistarol, higorrl1, savio.cantero, amaury.ufms\}@gmail.com
}

\begin{abstract}
This paper shows how digital inclusion was useful and necessary to consolidate the development of Federal University of Mato Grosso do Sul at Ponta Pora city. This campus was deployed through the government program called REUNI that performed expansion of the supply of higher education. The university sought more interaction with the local community, always aiming at the digital inclusion through Information and Communication Technologies (ICTs). Such interaction was achieved by actions and projects developed by the university and focused to the local audience. The Program called "NERDS da Fronteira" is described in this article, from its conception, through the goals, related actions and methods used, until its most recent results and impacts both the university and to society.
\end{abstract}

Resumo. Este artigo mostra como a inclusão digital foi útil e necessária para consolidação do Campus de Ponta Porã da UFMS, interior do estado de Mato Grosso do Sul, implantado através do Programa REUNI, de expansão da oferta do ensino superior. A universidade buscou maior interação com a comunidade local, tendo sempre como objetivo a inclusão digital através das TICs. Tal interação foi alcançada por ações e projetos desenvolvidos pela universidade e levadas ao público local. O Programa NERDS da Fronteira é retratado nesse artigo, desde sua concepção, passando pelos objetivos, ações vinculadas e métodos utilizados, até seus mais recentes impactos e resultados tanto para a universidade, quanto para a sociedade.

\section{Introdução}

A sociedade vivencia, atualmente, um processo de transformação, onde as Tecnologias da Informação e Comunicação (TICs) estão cada vez mais presentes, porém nem todos têm acesso a tais, devido a limitações. São necessárias ações de inclusão para mudar esse cenário. $\mathrm{O}$ ambiente escolar é um dos locais mais propícios para implementar estratégias de inclusão e acesso às TICs, pois os conhecimentos adquiridos pelos alunos através das matérias básicas do ensino podem ser aliados com as TICs, fazendo com que o aprendizado seja mais prático e agradável aos alunos.

A importância da utilização da tecnologia computacional na área educacional é indiscutível e necessária, seja no sentido pedagógico, seja no sentido social [Tajra, 2000]. Hoje, com o novo conceito de inteligência, em que podemos desenvolver as pessoas em suas diversas habilidades, o computador aparece num momento bastante oportuno, justamente incentivando e facilitando o desenvolvimento dessas habilidades. A universidade tem papel fundamental nesse processo através de projetos e ações de 
extensão, trazendo a população para dentro da universidade e também levando o ensino para fora e tornando possível a apropriação da inovação, promovendo espaços de comunicação, troca de experiências, cooperação e colaboração entre os diferentes atores deste cenário, conforme [Maciel et. al. 2012].

A recente e acelerada expansão da oferta do ensino superior no país, em especial em cidades do interior dos estados, promovidas por programas como o REUNI, vem fortalecer o papel da universidade socialmente atuante, favorecendo a criação de condições para a ampliação e permanência no ensino superior [REUNI 2007].

Este trabalho descreve e apresenta o impacto das ações de extensão realizadas pela Universidade Federal do Mato Grosso do Sul, Campus de Ponta Porã, através do Programa NERDS da Fronteira, visando promover o acesso às Tecnologias da Informação e Comunicação na sociedade local através de projetos e ações educacionais, dando ênfase à preparação de futuros talentos na área de matemática e computação.

\section{Histórico}

Em 2008 foi implantado em Ponta Porã, um novo campus da Universidade Federal de Mato Grosso do Sul, fruto da expansão da oferta do ensino superior promovida pelo REUNI, o Programa de Apoio a Planos de Expansão e Reestruturação das Universidades Federais. As atividades tiveram início em 2009, oferecendo dois cursos de graduação em Sistemas de Informação (Bacharelado) e Matemática (Licenciatura), ambos na área de exatas. Em 2010, foi implantado o curso de Ciência da Computação (Bacharelado) que fortaleceu, ainda mais, a vocação da unidade para a área das ciências exatas e tecnológicas.

A universidade, visando promover o acesso às TICs, criou projetos para que os professores e alunos de graduação tivessem contato com os alunos das escolas municipais e estaduais por meio de oficinas sobre robótica, programação e treinamentos para algumas das olimpíadas cientificas existentes. Desse modo, a instituição despertaria o interesse pelos cursos oferecidos na unidade, além de descobrir jovens talentos nesta área, ganhar visibilidade e aceitação da população local e consolidar sua presença no município, contribuindo para a geração de conhecimento e melhoria da formação de base dos alunos das escolas públicas da cidade.

\section{O Programa NERDS da Fronteira}

O termo NERDS é a sigla do Núcleo Educacional de Robótica e Desenvolvimento de Software da fronteira. O Programa é fruto da integração das ações de extensão propostas por servidores e acadêmicos do Campus de Ponta Porã (CPPP) da UFMS. Aproveitando-se da oferta de cursos na área das ciências exatas e tecnológicas, este programa apresenta-se como uma alternativa na busca e preparação de talentos nestas áreas, contribuindo com a melhoria da formação no estado de Mato Grosso do Sul. Um dos grandes desafios dessa proposta é despertar nos alunos do ensino fundamental e médio, o interesse e a motivação pelo estudo da matemática e do raciocínio lógico, como base para o seu desenvolvimento pessoal e profissional. O programa iniciou as suas atividades em 2009, utilizando recursos humanos e infraestrutura locais para a organização e realização de olimpíadas científicas, robótica educacional, cursos, oficinas e outros eventos e atividades que promovam o ensino da matemática e da 
computação, visando o desenvolvimento do raciocínio e outras habilidades e competências relacionadas.

A criação do Programa NERDS da Fronteira estimulou a organização e realização de ações de extensão, colocando à disposição da comunidade do município e da região, um conjunto de atividades que proporcionou a ampliação da formação educacional, enfatizando a interdisciplinaridade e a multidisciplinaridade, com a aplicação em áreas permeadas pelas ciências exatas e pela computação, bem como na interação contínua dos acadêmicos, corpo docente, corpo técnico e comunidade local no planejamento e execução de projetos diversificados de atividades nas áreas de ensino, pesquisa e extensão com a sociedade local, através de iniciativas de extensão vinculadas com a área de atuação do grupo, tais como ensino idiomas, cursos e palestras técnicas, atividades culturais e recreativas [Bogado et al, 2012].

Entre os objetivos do programa destacam-se a consolidação da presença e do processo de expansão da UFMS, em especial, com foco nos cursos das áreas de exatas, em consonância com os objetivos do REUNI na busca pela redução dos índices de evasão e melhoria das taxas de sucesso em cursos dessa área. A ideia é colaborar com a motivação dos estudantes visando ao fortalecimento das bases de conhecimento para a formação de engenheiros e técnicos em áreas que têm as ciências exatas e a computação como eixos. Portanto, a possibilidade de participação em um programa desta natureza propicia a toda a sociedade local uma vivência maior e mais ampla de todas as atividades que possam ser realizadas no âmbito da universidade e em favor da comunidade local.

\section{O Papel das Olimpíadas Científicas}

\subsection{Projeto Futuros Programadores de Ponta}

Entre os projetos coordenados pelo NERDS da fronteira um dos projetos que se destaca é o Futuros Programadores de Ponta, que prepara crianças de ensino fundamental e médio para as provas das Olimpíadas Brasileiras de Informática (OBI), competição organizada nos moldes das outras olimpíadas cientificas brasileiras.

Buscando dar suporte à OBI, o campus de Ponta Porã através do projeto Futuros Programadores de Ponta, se apresenta como sede de um curso de introdução à programação e à lógica, ministrados por acadêmicos do campus aos melhores colocados na fase do nível iniciação, fase esta que testa o raciocínio lógico dos alunos. $\mathrm{O}$ treinamento oferecido visa preparar os alunos para a fase programação da OBI e também incentivá-los a terem interesse pelas áreas em que o campus atua, tornando-os possíveis acadêmicos e futuros profissionais qualificados e com um bom raciocínio lógico e matemático, busca também treinar os professores para darem suporte aos alunos em suas respectivas escolas, possibilitando a realização das provas nas próprias escolas [Macena 2013].

Além dos motivos apresentados, acredita-se que esse contato entre os alunos das escolas e a universidade, seja excelente para a projeção do campus no município e, principalmente, que seja de fundamental importância para a criação de novas oportunidades a esses alunos, tanto em forma de conhecimento intelectual como também no conhecimento empírico, adquiridos pelo contato com os acadêmicos e os profissionais da instituição. 
Todos os participantes da OBI recebem certificados de participação. Os melhores colocados de cada modalidade recebem ainda medalhas. Os melhores colocados das modalidades Iniciação e Programação, em nível nacional, são convidados para uma semana de cursos no Instituto de Computação da UNICAMP [OBI 2014].

\subsection{A Robótica Educacional no Contexto Escolar}

A Robótica educacional é um campo que vem tomando destaque nas escolas brasileiras, pois atua nas diversas áreas do ensino, auxiliando os alunos no aprendizado e na fixação dos conteúdos ministrados, tornando o ensino mais prático e agradável tanto para o professor quanto para o aluno.

A Olimpíada Brasileira de Robótica (OBR) é uma das olimpíadas científicas brasileiras que se utiliza da temática da robótica, visando estimular os jovens estudantes às carreiras científico-tecnológicas, bem como identificar jovens talentosos e promover debates e atualizações no processo de ensino-aprendizagem brasileiro [OBR 2014].

Os bolsistas do Programa NERDS da Fronteira ministram um treinamento para os melhores alunos da modalidade teórica da OBR, visando a participação destes na modalidade prática da competição. O curso é dividido em duas etapas. Na primeira etapa é ministrado um curso de programação básica com a linguagem LOGO, proporcionando a aprendizagem de uma linguagem de programação ao mesmo tempo em que estimula a fixação de conceitos matemáticos. Na segunda etapa os alunos passam a utilizar o kit de robótica LEGO, onde é necessária aprendizagem de uma nova linguagem de programação, assim trabalhando com a lógica e reforçando os conceitos matemáticos.

O programa também dá suporte atividades de extensão envolvendo a robótica, tais como palestras, oficinas e cursos, ministrados em parcerias com as escolas do município.

\section{Resultados e Impactos}

Através dos recursos obtidos pelo programa NERDS, foi possível a aquisição de materiais e equipamentos que viabilizaram a criação do Laboratório de Robótica de Ponta Porã (LaRPP). Atualmente, a infraestrutura do LaRPP dá suporte aos projetos e ao desenvolvimento do ensino e da pesquisa, através de programas de iniciação científica e publicação de artigos em eventos nacionais e internacionais. Possibilita a participação dos acadêmicos em novas ações e linhas de pesquisa e conhecimento, voltadas para a área de dispositivos móveis, visão computacional, robótica, entre outras.

Além de tornar possível a participação de acadêmicos em provas e competições, nacionais e internacionais, como a Maratona de Programação, a Competição Brasileira de Robótica e a Competição Latino Americana de Robótica.

Outros resultados alcançados pela implantação e execução do programa NERDS da Fronteira tiveram impactos na sociedade de Ponta Porã. Entre eles: (1) Organização e realização da OBI nos anos de 2010 (100 inscritos), 2011 (200 inscritos), 2012 (500 inscritos), 2013 (1.800 inscritos), 2014 (2.700 inscritos), com 3 classificados para fase 2 da programação júnior e 151 classificados para a fase 2 na modalidade iniciação (teórica); (2) Organização e realização local das provas da OBR nos anos de 2012 (760 inscritos), 2013 (2.400 inscritos), 2014 (3.500 inscritos); (3) Apoio a projetos escolas de 
robótica educacional, com treinamentos e cursos sobre robótica, junto às escolas João Brembatti Calvoso e Ignês Andreazza, que já possuem ações nesse sentido.

\section{Considerações Finais}

O Programa NERDS da Fronteira é, atualmente, o principal programa de extensão do Campus de Ponta Porã. A ação se consolidou na universidade, colaborando também com a consolidação da universidade no munícipio. O programa abrange diversos projetos com várias trilhas a serem tomadas, mas todos têm a inclusão digital como um dos seus objetivos.

Dentre os projetos que o programa NERDS abrange, se destaca o projeto Futuros Programadores de Ponta, este que foi abordado nesse artigo. O projeto visa oferecer treinamentos para o maior número de alunos, das escolas de Ponta Porã e região, que se interessarem por participar de alguma olimpíada científica (por exemplo, OBMEP, OBI, OBR). Muitas dessas ações estão descritas no blog do programa [NERDS 2014]. O projeto é executado por acadêmicos do CPPP, coordenado por um docente do campus e possui o apoio e o suporte de um Grupo PET.

Desde 2010, início do projeto, o número de inscritos no OBI vem crescendo, graças ao incentivo vindo das escolas para os alunos, fruto dos primeiros trabalhos realizados pelo projeto Futuro Programadores de Ponta. É um dos indícios de que o projeto cresceu com o passar dos anos, e que também se consolidou junto com o programa NERDS da Fronteira.

\section{Referências Bibliográficas}

BOGADO, G. L., VAES, R. G., CASTRO JR, A. A., SILVA, A. A., RODRIGUES, C. E., SANTOS JR, G. A., STEFFEN, A. M. A. \& CHICOSKI, J. T. (2012). O Programa NERDS da Fronteira. Anais do Primeiro Seminário Nacional de Inclusão Digital (SENID 2012), Passo Fundo, RS.

MACENA, G. S. ; SILVA, R. S. ; CASTRO, A. A. . Software Educacional Móvel de Apoio para Preparação das Olimpíadas Científicas. RETEC - Revista de Exatas e Tecnologia, Edição Especial - ERI-MT 2013, http://www.retec.eti.br, 2013.

MACIEL, Marcia; LEITE, Raquel Machado; PASSERINO, Liliana M. Cinco anos de Ceibal: a inclusão digital e suas mudanças nas comunidades fronteiriças. In: Anais do Workshop de Informática na Escola. 2012.

NERDS - Blog do programa NERDS da Fronteira, http://nerdsdafronteira.blogspot.com.br/, Junho/2014.

OBI - Olimpíada Brasileira de Informática, http://olimpiada.ic.unicamp.br/, Junho/2014.

OBR - Olimpíada Brasileira de Robótica, http://www.obr.org.br, Julho/2014.

REUNI - Decreto $\mathrm{n}^{\circ}$ 6.096, de 24 de abril de 2007. Institui o Programa de Apoio a Planos de Reestruturação e Expansão das Universidades Federais - REUNI, http://www.planalto.gov.br/ccivil_03/_Ato2007-2010/2007/Decreto/D6096.htm, Julho/2014.

TAJRA, Sanmya Feitosa. Informática na educação - Novas ferramentas pedagógicas para o professor da atualidade. Editora Érica, 2000. 